\title{
Sistem Pakar Untuk Identifikasi Jenis Jerawat Dengan Metode Certainity Factor
}

\author{
Dedi Rahman Habibie ${ }^{1}$, Dasril Aldo ${ }^{2}$ \\ ${ }^{1}$ dedi.habibi@gmail.com, 2dasrilaldo1994@gmail.com, \\ Program Studi Sistem Informasi, STMIK GICI Batam
}

\begin{abstract}
Acne is a skin problem that results from overproduction of oil which causes inflammation and inflammation in human skin. By using a certain factor method is able to produce a diagnosis of the type of user spent so that treatment advice will be given that is suitable for patients. Factor Method Specific factors to prove whether it is certain or not, the form of metrics that are usually used in expert systems. This method is very suitable for expert systems in diagnosing something that is uncertain. The advantage of the first certainty factor method is to present qualitative data. Second, the Certainty Factor method has the ability to increase the degree of confidence. The results obtained with this system can help patients in diagnosing acne that is obtained from knowledge of the problem and solutions to deal with the type of acne. And in the expert system provides information to the public that is more accurate and precise like a specialist in classifying the types of acne on the face, and facilitating the public to better understand classified as improving the types of acne on the face produced.
\end{abstract}

Intisari-Jerawat adalah gangguan pada kulit akibat dari kelebihan produksi kelenjar minyak yang menyebabkan terjadinya infeksi dan radang pada kulit manusia. Dengan menggunakan metode Certainity Factor mampu menghasilkan diagnosa jenis dari jerawat yang dialami user, sehingga nantinya akan diberikan saran perawatan yang cocok bagi pasien. Metode Certainity Factor untuk membuktikan apakah suatu fakta itu pasti atau tidak, berbentuk metrik yang biasanya digunakan dalam sistem pakar. Metode ini sangat cocok digunakan untuk sistem pakar dalam mendiagnosis sesuatu yang belum pasti. Keunggulan dari metode Certainity Factor yang pertama dalam mempersentasikan data-data kualitatif. Kedua, metode Certainity Factor memiliki kemampauan untuk mengekspresikan derajat keyakinan. Hasil yang diperoleh dengan sistem ini, dapat membantu pasien dalam mendiagnosa penyakit jerawat yang didapatkan dari pengetahuan mengenai gejala serta solusi penanganan terhadap jenis jerawat. Serta dalam sistem pakar ini memberi informasi kepada masyarakat yang lebih akurat dan tepat layaknya dokter spesialis dalam menggolongkan jenis jerawat pada wajah, dan memudahkan masyarakat lebih mengetahui tergolong manakah dalam menggolongkan jenis jerawat pada wajah yang dialami.
Kata Kunci-Sistem Pakar; Jerawat; Certainity factor; Identifikasi

\section{PENDahuluaN}

Perkembangan teknologi informasi mengalami kemajuan yang sangat pesat, hal tersebut dikarenakan oleh kekuatan era globalisasi dimana komputer dan internet dengan sifatnya yang dinamis merupakan fasilitas yang telah mendominasi berbagai aktivitas kehidupan seperti pendidikan, perkantoran, industri, kesehatan dan lain-lain [1]. Teknologi di bidang kesehatan atau kedokteran juga telah menerapkan peran yang sangat signifikan untuk menolong jiwa manusia dan riset di bidang kedokteran. Dengan berkembangnya teknologi informasi di bidang kesehatan sangatlah membantu orangorang yang bergerak di bidang kesehatan dalam melakukan pekerjaannya [2]. Para pakar/ahli bisa dengan cepat menangani para pasien dan mendiagnosis penyakit yang mereka derita. Pemanfaatan teknologi informasi ini semoga bisa mendukung peningkatan kualitas kerja di bidang kesehatan.

Di bidang kesehatan sendiri, pemanfaatan teknologi dimanfaatkan hampir di semua penjuru misalnya dalam hal yang paling sederana saja. Yaitu pengecekan suhu tubuh menggunakan Termometer sampai yang paling baru adalah penyambungan sel kulit dan tulang menggunakan Chip khusus yang baru - baru ini telah di teliti oleh Ohio University [3]. Kecerdasan buatan yang biasa disingkat AI (Artificial Intelligence) merupakan ilmu tentang bagaimana membangun suatu sistem komputer yang menunjukkan kecerdasan dalam berbagai cara [4]. AI merupakan area penelitian yang dinamis dalam topik riset ilmu komputer. Sampai saat ini, telah banyak penelitian mengenai perkembangan AI diantaranya neural network, evolutionary computing, machine learning, natural language processing, dan object oriented programming [5]. Munculnya teknologi kecerdasan buatan dalam bidang kesehatan memacu pengembangan aplikasi sistem pakar untuk layanan kesehatan [6].

Sistem pakar atau sistem berbasis pengetahuan atau sistem pengetahuan adalah sistem komputer yang dicirikan oleh fakta bahwa perbedaan eksplisit dibuat antara bagian di mana pengetahuan tentang domain masalah direpresentasikan dan bagian yang memanipulasi pengetahuan tersebut untuk memecahkan masalah aktual dengan menggunakan problem data [7] 


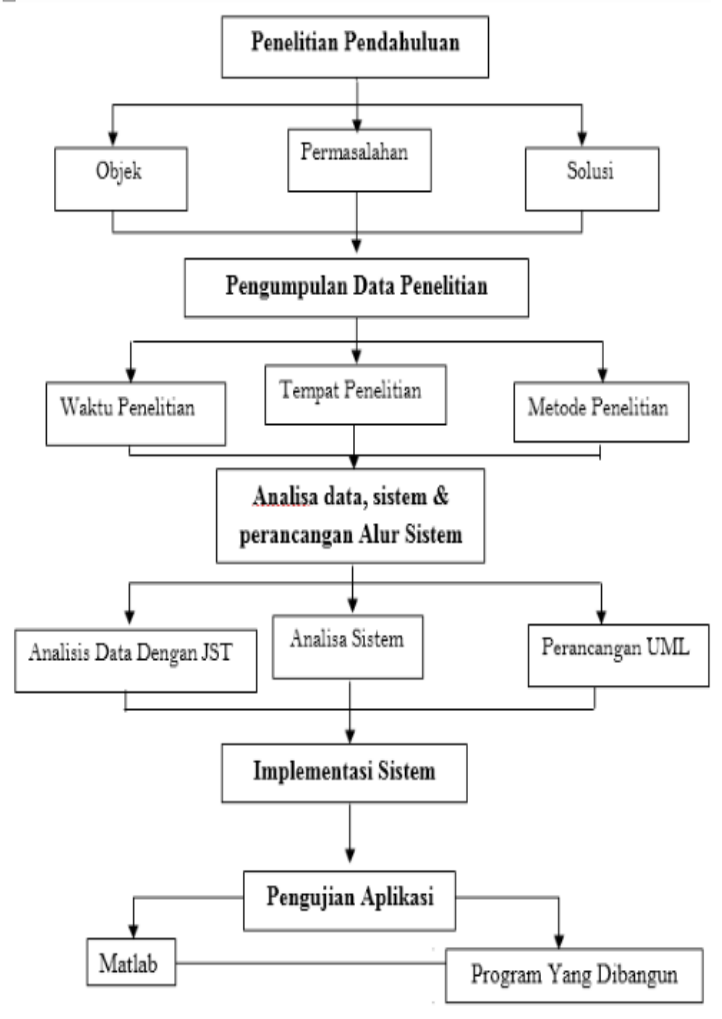

Gambar 1. Metodologi Penelitian

Sistem pakar dapat disebut juga sebagai salah satu cabang dari AI yang membuat penggunaan secara luas knowledge yang khusus untuk penyelesaian masalah tingkat manusia yang pakar [8]. Seorang pakar adalah orang yang mempunyai keahlian dalam bidang tertentu, yaitu pakar yang mempunyai knowledge atau kemampuan khusus yang orang lain tidak mengetahui atau mampu dalam bidang yang dimilikinya. Pada saat pertama kali sekitar tahun 70-an, sistem pakar hanya berisi knowledge yang eksklusif. Namun demikian sekarang ini istilah sistem pakar sudah digunakan untuk berbagai macam sistem yang menggunakan teknologi sistem pakar itu [9].

Metode yang digunakan pada penelitian kali ini ialah metode factor kepastian (certainty factor), metode ini merupakan suatu metode untuk membuktikan ketidakpastian pemikiran seorang pakar, dimana untuk mengakomodasi hal tersebut seseorang biasanya menggunakan certainty factor untuk menggambarkan tingkat keyakinan pakar terhadap masalah yang sedang dihadapi [10]. Jerawat merupakan timbunan kelenjar minyak pada kulit yang terlalu aktif yang tersumbat oleh kotoran dan terjadi infeksi karena adanya bakteri Staphylococcus aureus. Jerawat biasanya muncul pada permukaan kulit wajah, leher, dada dan punggung pada saat kelenjar minyak pada kulit terlalu aktif sehingga pori-pori kulit akan tersumbat oleh timbunan lemak yang berlebihan [11]. Jika timbunan itu bercampur dengan keringat, debu dan kotoran lain, maka akan menyebabkan timbunan lemak dan bintik hitam di atasnya yang disebut komedo. Pada komedo terdapat bakteri, maka terjadilah peradangan yang dikenal dengan jerawat yang ukurannya bervariasi mulai dari ukuran kecil sampai ukuran besar serta berwarna merah, kadangkadang bernanah serta menimbulkan rasa nyeri [12].
Obat paling ampuh untuk menghilangkan jerawat yang membandel adalaha dengan menggunakan beberapa tanaman obat herbal seperti : aloe vera, amaranth, arnica, asparagus, barberry, basil, birch, bittersweet nightshade, ragi brewer, burdock, calendula, celandine, chaste tree, chaste berry, coriander, cur cumin, teh hijau, guggul, minyak jojoba, kalibromatum, teh labrador, serta lavender [13]. Hasil dari penelitian yang telah dilakukan oleh peneliti, menemukan beberapa jenis jerawat, antara lain yaitu jerawat blackhead, whitehead, papula, pustula, nodul, kista, conglobata dan fluminan. Berdasarkan dari jenis jerawat tersebut memiliki tingkat kelompoknya masing-masing, yaitu dari tingkat ringat, sedang dan parah [14]. Namun, kebanyakan penderita jerawat masih banyak yang belum mengetahui jenis-jenis jerawat tersebut, jika mengalami jerawat dan tidak langsung ditangani akan berkembang menjadi parah, sehingga menyebabkan kerusakan pada kulit berupa jaringan parut dan meninggalkan bekas luka [15].

\section{METODE PENELITIAN}

Agar penelitian ini lebih terarah dan bisa mencapai tujuan yang penulis harapkan, maka diperlukan kerangka kerja penelitian seperti pada Gambar 1. Metodologi penelitian pada Gambar 1 terbagi menjadi lima tahpan. Pertama penelitian pendahuluan dari objek, permasalahan dan solusi. Berikutnya pengumpulan data penelitian yang proses waktu penelitian, tempat penelitian dan waktu penelitian. Selanjutnya analisis data, sistem dan perancangan alur sistem.Bagian ini memiliki tahap analisis data dengan jaringan syaraf tiruan, analisis sistem dan perancangan UML. Kemudian implelmentasi sistem dari beberapa tahapan sebelumnya. Tahap terakhir yaitu pengujian aplikasi yang terdiri matlab dan program yang dibangun. 
III. HASIL DAN PEMBAHASAN

Berikut data yang didapat mengenai penyakit Jenis Jerawat Pada Wajah pada Tabel 1 dan Tabel 2:

Tabel 1. Penyakit Jerawat

\begin{tabular}{|c|c|c|}
\hline NO & KP & Jenis Penyakit \\
\hline 1 & J01 & Blackhead \\
\hline 2 & J02 & Papula \\
\hline 3 & J03 & Pustula \\
\hline 4 & J04 & Nodul \\
\hline 5 & J05 & Kista \\
\hline 6 & J06 & Conglobata \\
\hline 7 & J07 & Fluminans \\
\hline 8 & J08 \\
\hline
\end{tabular}

Tabel 2. Gejala Penyakit Jerawat

\begin{tabular}{|c|c|}
\hline KD & GEJALA \\
\hline GE01 & $\begin{array}{l}\text { Terdapat Benjolan Kecil Dan Sedikit } \\
\text { Menonjol Serta Berwarna Gelap Pada Kulit }\end{array}$ \\
\hline GE02 & Terdapat Selkulit Mati Pada Wajah \\
\hline GE03 & Kulit Berminyak \\
\hline GE04 & Wajah Terasa Gatal \\
\hline GE05 & $\begin{array}{l}\text { Benjolan Pada Wajah Dengan } \\
\text { Bewarna Putih Tapi Tidak Sakit }\end{array}$ \\
\hline GE06 & Terdapat Ruam Pada Kulit \\
\hline GE07 & $\begin{array}{l}\text { Terdapat Benjolan Kecil Bwarna Merah } \\
\text { Yang Bila Di Sentuh Terasa Sakit }\end{array}$ \\
\hline GE08 & $\begin{array}{l}\text { Benjolan Kecil-Kecil Terdapat Nanah Pada } \\
\text { Ujung }\end{array}$ \\
\hline GE09 & 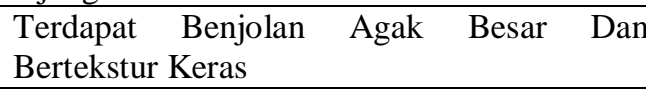 \\
\hline GE10 & $\begin{array}{l}\text { Benjolan Besar Berisi Nanah Yang Terasa } \\
\text { Sakit }\end{array}$ \\
\hline GE11 & $\begin{array}{l}\text { Terdapat Benjolan-Bnjolan } \\
\text { Berklompok Pada Wajah }\end{array}$ \\
\hline GE12 & Sangat Keras Dan Padat \\
\hline GE13 & Terdapat Lesi Pada Wajah \\
\hline GE14 & Fluktuatif Demam \\
\hline GE15 & Nyeri Sendi Dengan Pembengkakan \\
\hline GE16 & Berat Badan Dan Kurang Nafsu Makan \\
\hline GE17 & $\begin{array}{lccc}\text { Jerawat Ulserasi } & \text { Dan } & \text { Inflamasi } & \text { Pada } \\
\text { Punggung Dan Dada } & & & \\
\end{array}$ \\
\hline
\end{tabular}

JOINTECS Vol. 4, No.3, September 2019

DOI: https://doi.org/10.31328/jointecs.v4i3.1055
Selanjutnya ditentukan bobot jawaban dari user sebagai nilai yang digunakan dalam perhitungan metode $\mathrm{CF}$ yang tertera pada Tabel 3:

Tabel 3. Nilai Bobot Jawaban

\begin{tabular}{|c|c|}
\hline Uncertain Term & CF \\
\hline Pasti tidak & 0,1 \\
\hline Hampir pasti tidak & 0,2 \\
\hline Kemungkinan besar tidak & 0,3 \\
\hline Mungkin tidak & 0,4 \\
\hline Tidak tahu & 0,5 \\
\hline Mungkin & 0.6 \\
\hline Kemungkinan besar & 0.7 \\
\hline Hampir pasti & 0.8 \\
\hline Pasti & 1.0 \\
\hline
\end{tabular}

Selanjutnya akan dibuatkan rule yang digunakan sebagai aturan untuk menganalisa jawabn dari pasien, berikut adalah rule yang telah ditetakan:

\section{[R1] IF G01 AND G02 AND G03 AND G04 THEN J01} $(\mathrm{CF}=0,85)$

[R2] IF G01 AND G03 AND G04 THEN J01 (CF=0,55)

[R3] IF G02 AND G03 AND G04 AND G05 THEN J02 $(\mathrm{CF}=0,88)$

[R4] IF G02 AND G04 AND G05 THEN J02 (CF=0,50)

[R5] IF G03 AND G04 AND G06 AND G07 THEN J03 $(\mathrm{CF}=0,83)$

[R6] IF G03 AND G06 AND G07 THEN J03 (CF=0,50)

[R7] IF G02 AND G03 AND G04 AND G08 THEN $\mathrm{J} 04(\mathrm{CF}=0,8)$

[R8] IF G02 AND G03 AND G08 THEN J04 (CF=0,69)

[R9] IF G02 AND G03 AND G04 AND G09 THEN $\mathrm{J} 05(\mathrm{CF}=0,8)$

[R10] IF G02 AND G04 AND G09 THEN J05 (CF=0,69)

[R11] IF G03 AND G04 AND G10 THEN J06 (CF=0,73)

[R12] IF G03 AND G11 AND G12 AND G13 THEN J07 $(\mathrm{CF}=0,83)$

[R13] IF G03 AND G12 AND G13 THEN J07 (CF=0,58)

[R14] IF G14 AND G15 AND G16 AND G17 AND G18 THEN J08 $(\mathrm{CF}=0,88)$

[R15] IF G15 AND G16 AND G17 AND G18 THEN J08 $(\mathrm{CF}=0,75)$

\subsection{Proses Perhitungan Dengan CF}

Adapun proses yang dilakukan sebagai berikut :

1. Menentukan data yang akan dianalisa, dimana data yang akan dianalisa adalah data yang terdapat pada form berikut ini: 
Formulir Pasien

Nama

Usia

- Dasril Aldo

Jenis Kelamin

: 27

Tanggal Konsultasi

: L

:20 Oktober 2018

Pertanyaan Gejala:

\begin{tabular}{|c|c|c|}
\hline NO & Gejala & Jawaban \\
\hline 1 & $\begin{array}{l}\text { Terdapat Benjolan Kecil Dan } \\
\text { Sedikit Menonjol Serta Berwarna } \\
\text { Gelap Pada Kulit }\end{array}$ & Tidak \\
\hline 2 & $\begin{array}{l}\text { Terdapat Selkulit Mati Pada } \\
\text { Wajah }\end{array}$ & Tidak \\
\hline 3 & Kulit Berminyak & $\begin{array}{c}\text { Sangat } \\
\text { Berminyak }\end{array}$ \\
\hline 4 & Wajah Terasa Gatal & $\mathrm{Ya}$ \\
\hline 5 & $\begin{array}{l}\text { Benjolan Pada Wajah Dengan } \\
\text { Ujung Bewarna Putih Tapi Tidak } \\
\text { Sakit }\end{array}$ & Tidak \\
\hline 6 & Terdapat Ruam Pada Kulit & Agak Jelas \\
\hline 7 & $\begin{array}{l}\text { Terdapat Benjolan Kecil Bwarna } \\
\text { Merah Yang Bila Di Sentuh } \\
\text { Terasa Sakit }\end{array}$ & $\begin{array}{l}\text { Berwarna \& } \\
\text { Sakit }\end{array}$ \\
\hline 8 & $\begin{array}{l}\text { Benjolan Kecil-Kecil Terdapat } \\
\text { Nanah Pada Ujung }\end{array}$ & Tidak \\
\hline 9 & $\begin{array}{l}\text { Terdapat Benjolan Agak Besar } \\
\text { Dan Bertekstur Keras }\end{array}$ & Tidak \\
\hline 10 & $\begin{array}{l}\text { Benjolan Besar Berisi Nanah } \\
\text { Yang Terasa Sakit }\end{array}$ & Tidak \\
\hline 11 & $\begin{array}{l}\text { Terdapat Benjolan-Bnjolan Besar } \\
\text { Berklompok Pada Wajah }\end{array}$ & Tidak \\
\hline 12 & $\begin{array}{l}\text { Benjolan Sangat Keras Dan } \\
\text { Padat }\end{array}$ & Tidak \\
\hline 13 & Terdapat Lesi Pada Wajah & Tidak \\
\hline 14 & Fluktuatif Demam & Tidak \\
\hline 15 & $\begin{array}{l}\text { Nyeri Sendi Dengan } \\
\text { Pembengkakan }\end{array}$ & Tidak \\
\hline 16 & $\begin{array}{l}\text { Berat Badan Dan Kurang Nafsu } \\
\text { Makan }\end{array}$ & Tidak \\
\hline 17 & $\begin{array}{l}\text { Jerawat Ulserasi Dan Inflamasi } \\
\text { Pada Punggung Dan Dada }\end{array}$ & Tidak \\
\hline 18 & Penurunan Aktivitas Fisik & $\mathrm{Ya}$ \\
\hline
\end{tabular}

Dari jawaban tesebut yang diberikan oleh pasien pertama akan dibuatkan fakta gejalanya seperti padaTabel 4:

Tabel 4. Fakta Gejala

\begin{tabular}{|c|c|c|}
\hline Fakta & Ket & Bobot \\
\hline G01 & Evidence & 0 \\
\hline G02 & Evidence & 0 \\
\hline G03 & Evidence & 1 \\
\hline G04 & Evidence & 1 \\
\hline G05 & Evidence & 0 \\
\hline G06 & Evidence & 0,8 \\
\hline G07 & Evidence & 0,8 \\
\hline G08 & Evidence & 0 \\
\hline G09 & Evidence & 0 \\
\hline G10 & Evidence & 0 \\
\hline G11 & Evidence & 0 \\
\hline G12 & Evidence & 0 \\
\hline G13 & Evidence & 0 \\
\hline G14 & Evidence & 0 \\
\hline G15 & Evidence & 0 \\
\hline G16 & Evidence & 0 \\
\hline G17 & Evidence & 0 \\
\hline G18 & Evidence & 1 \\
\hline
\end{tabular}

[R1] IF G01 (CF =0 ) AND G02 (CF = 0$)$ AND G03 (CF $=1)$ AND G04 $(\mathrm{CF}=1)$ THEN J01 $(\mathrm{CF}=0,85)$

CF1 (G01, G02, G03 , G04 )

$=\operatorname{Min}[0 ; 0 ; 1 ; 1 ;]^{*} 0,85$

$=0 * 0,85$

$=0$

Fakta Baru :

J01 Blackhead $\mathrm{CF}=0$

[R2] IF G01 (CF =0) AND G03 (CF = 1) AND G04 (CF $=1$ ) THEN J01 $(\mathrm{CF}=0,55)$

CF2 (G01, G03 , G04 )

$=\operatorname{Min}[0 ; 1 ; 1 ;]^{*} 0,55$

$=0 * 0,55$

$=0$

Fakta Baru :

J01 Blackhead $\mathrm{CF}=0$

[R3] IF G02 (CF =0 ) AND G03 (CF = 1) AND G04 (CF

$=1)$ AND G05 $(\mathrm{CF}=1)$ THEN J02 $(\mathrm{CF}=0,88)$

CF3 (G02, G03 ,G04, G05 )

$=\operatorname{Min}[0 ; 0 ; 1 ; 1 ;]^{*} 0,88$

$=0 * 0,88$

$=0$

Fakta Baru :

$\mathrm{J} 02$ Whitehead $\mathrm{CF}=0$

[R4] IF G02 (CF =0 ) AND G04 (CF = 0$)$ AND G05 (CF

= 1) THEN J02 $(\mathrm{CF}=0,50)$

CF4 (G02, G04,G05 )

$=\operatorname{Min}[0 ; 0 ; 1 ;]^{*} 0,50$

$=0 * 0,50$

$=0$

Fakta Baru :

$\mathrm{J} 02$ Whitehead $\mathrm{CF}=0$

[R5] IF G03 (CF =1 ) AND G04 (CF = 1$)$ AND G06 (CF $=0,8)$ AND G07 $(\mathrm{CF}=0,8)$ THEN J03 $(\mathrm{CF}=0,83)$

CF5 (G03, G04 ,G06 , G07 )

$=\operatorname{Min}[1 ; 1 ; 0,8 ; 0,8 ;]^{*} 0,83$

$=0,8 * 0,83$ 
$=0,664$

Fakta Baru :

J03 Papula $\mathrm{CF}=0,664$

[R6] IF G03 (CF =1 ) AND G06 (CF = 0,8) AND G07

$(\mathrm{CF}=0,8)$ THEN J03 $(\mathrm{CF}=0,50)$

CF6 (G03, G06,G07)

$=\operatorname{Min}[1 ; 0,8 ; 0,8 ;]^{*} 0,50$

$=0,8 * 0,50$

$=0,4$

Fakta Baru :

J03 Papula $\mathrm{CF}=0,4$

[R7] IF G02 (CF =0) AND G03 (CF = 1) AND G04 (CF

= 1) AND G08 $(\mathrm{CF}=0)$ THEN J04 $(\mathrm{CF}=0,80)$

CF7 (G02, G03, G04, G08 )

$=\operatorname{Min}[0 ; 1 ; 1 ; 0]^{*} 0,80$

$=0 * 0,80$

$=0$

Fakta Baru :

$\mathrm{J} 04$ Pustula $\mathrm{CF}=0$

[R8] IF G02 (CF =0) AND G03 (CF = 0$)$ AND G08 (CF

= 1) THEN J04 $(\mathrm{CF}=0,69)$

CF8 (G02, G03, G08 )

$=\operatorname{Min}[0 ; 0 ; 1] * 0,69$

$=0 * 0,69$

$=0$

Fakta Baru :

J04 Pustula $\mathrm{CF}=0$

[R9] IF G02 (CF =0) AND G03 (CF = 0$)$ AND G04 (CF

= 1) AND G09 $(\mathrm{CF}=1)$ THEN J05 $(\mathrm{CF}=0,80)$

CF9 (G02, G03 ,G04, G09)

$=\operatorname{Min}[0 ; 0 ; 1 ; 1 ;]^{*} 0,80$

$=0 * 0,80$

$=0$

Fakta Baru :

J05 Nodul $\mathrm{CF}=0$

[R10] IF G02 (CF =0 ) AND G04 (CF = 0$)$ AND G09 (CF

$=1$ ) THEN J05 $(\mathrm{CF}=0,69)$

CF10 (G02, G04,G09)

$=\operatorname{Min}[0 ; 0 ; 1 ;]^{*} 0,69$

$=0 * 0,69$

$=0$

Fakta Baru :

J06 Nodul CF $=0$

[R11] IF G03 (CF =0) AND G04 (CF = 0 ) AND G10 (CF

= 1) THEN J06 $(\mathrm{CF}=0,73)$

CF11 (G03, G04,G10)

$=\operatorname{Min}[0 ; 0 ; 1 ;]^{*} 0,73$

$=0 * 0,73$

$=0$

Fakta Baru :

$$
\text { J07 Kista CF }=0
$$

[R12] IF G03 (CF =0) AND G11 (CF = 0$)$ AND G12 (CF $=1)$ AND G13 $(\mathrm{CF}=1)$ THEN J07 $(\mathrm{CF}=0,83)$

CF12 (G03, G11 ,G12, G13 )

$=\operatorname{Min}[0 ; 0 ; 1 ; 1 ;]^{*} 0,83$

$=0 * 0,83$

$=0$

Fakta Baru :

J07 Conglobata $\mathrm{CF}=0$
[R13] IF G03 (CF =0 ) AND G12 (CF = 0$)$ AND G13 (CF = 1) THEN J07 $(\mathrm{CF}=0,58)$

CF1 (G03, G12,G13)

$=\operatorname{Min}[0 ; 0 ; 1 ; 1 ;]^{*} 0,58$

$=0 * 0,58$

$=0$

Fakta Baru :

J07 Conglobata $\mathrm{CF}=0$

[R14] IF G14 (CF =0) AND G15 (CF = 0$)$ AND G16 (CF $=1)$ AND G17 $(\mathrm{CF}=1)$ AND G18 (CF = 1 )THEN J08 (CF=0,88)

CF14 (G14, G15 ,G16, G17, G18 )

$=\operatorname{Min}[0 ; 0 ; 1 ; 1 ; 1]^{*} 0,88$

$=0 * 0,88$

$=0$

Fakta Baru :

J08 Fluminans $\mathrm{CF}=0$

[R15] IF G15 (CF =0) AND G16 (CF = 0$)$ AND G17 (CF = 1) AND G18 $(\mathrm{CF}=1)$ THEN J08 $(\mathrm{CF}=0,75)$

CF15 (G15, G16 ,G17, G18 )

$=\operatorname{Min}[0 ; 0 ; 1 ; 1 ;]^{*} 0,75$

$=0 * 0,75$

$=0$

Fakta Baru :

J08 Fluminans $\mathrm{CF}=0$

Dari fakta baru diatas maka nilai hasil CF nya akan dibuatkan tabel nya seperti yang ditunjukan Tabel 5:

Tabel 5. Hasil Nilai CF Baru

\begin{tabular}{|c|c|c|c|}
\hline Rule & Fakta Baru & KET & Nilai CF \\
\hline R1 & J01 & Hypothesis & 0 \\
\hline R2 & J01 & Hypothesis & 0 \\
\hline R3 & J02 & Hypothesis & 0 \\
\hline R4 & J02 & Hypothesis & 0 \\
\hline R5 & J03 & Hypothesis & 0,664 \\
\hline R6 & J03 & Hypothesis & 0,4 \\
\hline R7 & J04 & Hypothesis & 0 \\
\hline R8 & J04 & Hypothesis & 0 \\
\hline R9 & J05 & Hypothesis & 0 \\
\hline R10 & J05 & Hypothesis & 0 \\
\hline R11 & J06 & Hypothesis & 0 \\
\hline R12 & J07 & Hypothesis & 0 \\
\hline R13 & J07 & Hypothesis & 0 \\
\hline R14 & J08 & Hypothesis & 0 \\
\hline R15 & J08 & Hypothesis & 0 \\
\hline
\end{tabular}

Dari tabel diatas terdapat kesamaan hasil hipotesis yaitu pada rule 1 sampai dengan rule 2 merupakan hipotesisi J01, Rule 3 sampai dengan 4 J02, Rule 5 sampai dengan 6 J03 dan Rule 7 sampai dengan 8 J04, Rule 9 sampai dengan 10 J05 dan Rule 11 sampai J06, Rule 12 sampai dengan 13 J07dan Rule 14 sampai dengan 15 J08, sehingga dilakukan penggabungan terhadap rule-rule tesebut seperti berikut:

1. HIPOTESIS J01 = Blackhead

Hasil Hipotesa Rule 1 dan Rule 2 adalah 0, Maka tidak perlu penggabungan karna nilai akan tetap 0

Fakta Baru :

J01 Blackhead Hypothesis CF 0\% 
2. HIPOTESIS J02 = Whitehead

Hasil Hipotesa Rule 3 dan Rule 4 adalah 0, Maka tidak perlu penggabungan karna nilai akan tetap 0

\section{Fakta Baru :}

J02 Hypothesis Whitehead CF 0\%

3. HIPOTESIS J03 = Papula

$C F_{\text {Combine }} C F(H, E)_{\text {old } 1}=C F(H, E)_{r 5}+$

$C F(H, E)_{r 6} *\left[1-C F(H, E)_{r 5}\right]$

$=0,664+\left(0,4^{*}[1-0,664]\right)$

$=0,664+(0,4 * 0,336)$

$=0,7984_{\text {old }}$

Keterangan: CFold terakhir merupakan CF Penyakit Papula, berdasarkan hasil perhitungan $\mathrm{CF}$ di atas, maka CF penyakit Papula adalah 0,7984. Selanjutnya hitung persentase keyakinan terhadap penyakit dengan persamaan

$$
\begin{aligned}
\text { Persentase } & =C F_{\text {penyakit }} * 100 \\
& =0,7984 * 100 \\
& =0,7984 \%
\end{aligned}
$$

\section{Fakta Baru :}

J03 Hypothesis Papula CF 79,84 \%

4. HIPOTESIS J04 = Pustula

Hasil Hipotesa Rule 7 dan Rule 8 adalah 0, Maka tidak perlu penggabungan karna nilai akan tetap 0

\section{Fakta Baru :}

J04 Hypothesis Pustula CF 0\%

5. HIPOTESIS J05 = Nodul

Hasil Hipotesa Rule 9 dan Rule 10 adalah 0, Maka tidak perlu penggabungan karna nilai akan tetap 0

\section{Fakta Baru :}

J05 Hypothesis Nodul CF 0\%

6. HIPOTESIS J06 = Kista

Hasil Hipotesa Rule Rule 11 adalah 0, Maka tidak perlu penggabungan karna nilai akan tetap 0

Fakta Baru :

J06 Hypothesis Kista CF 0\%

7. HIPOTESIS J07 = Conglobata

Hasil Hipotesa Rule 12 dan Rule 13 adalah 0, Maka tidak perlu penggabungan karna nilai akan tetap 0

Fakta Baru :

J07 Hypothesis Conglobata CF 0\%

8. HIPOTESIS J08 = Fluminans

Hasil Hipotesa Rule 14 dan Rule 15 adalah 0, Maka tidak perlu penggabungan karna nilai akan tetap 0

\section{Fakta Baru :}

J08 Hypothesis Fluminans CF 0\%

Dari hasil pencarian $\mathrm{CF}$ terhadap masing-masing penyakit diatas, maka hasilnya akan dibandingkan untuk mendapatkan hasil diagnosa akhir dari pernyakit tersebut:

$\begin{array}{llc}\text { 1. } & \text { Blackhead } & 0 \% \\ \text { 2. } & \text { Whitehead } & 0 \% \\ \text { 3. } & \text { Papula } & 79,84 \% \\ \text { 4. } & \text { Pustula } & 0 \% \\ \text { 5. Nodul } & 0 \% \\ \text { 6. Kista } & 0 \% \\ \text { 7. } & \text { Conglobata } & 0 \% \\ \text { 8. } & \text { Conglobata } & 0 \%\end{array}$

Dari hasil diatas, maka pasien didaignosa penyakit Papula dengan nilai CF 79,84\%.

\section{KESIMPULAN DAN SARAN}

Dengan menggunakan sistem ini, dapat membantu pasien dalam mendiagnosa penyakit jerawat yang didapatkan dari pengetahuan mengenai gejala serta solusi penanganan terhadap jenis jerawat. Aplikasi sistem pakar ini memberi informasi kepada masyarakat yang lebih akurat dan tepat layaknya dokter spesialis dalam menggolongkan jenis jerawat pada wajah, dan memudahkan masyarakat lebih mengetahui tergolong manakah dalam menggolongkan jenis jerawat pada wajah yang dialami. Aplikasi sistem pakar ini untuk masyarakat dapat mengetahui informasi lebih cepat tentang dalam menggolongkan jenis jerawat pada wajah yang di alami dan melakukan penanganan lebih awal dalam menggolongkan jenis jerawat pada wajah.

\section{DAFTAR PUSTAKA}

J. Vol and N. Mei, "BLENDED LEARNING DAN KEMANDIRIAN BELAJAR MAHASISWA TEKNOLOGI PENDIDIKAN," vol. 2, no. 2, pp. 109 $114,2019$.

R. A. Supono, F. I. Komputer, U. Gunadarma, J. M. Raya, and P. Cina, "PENERAPAN TEKNOLOGI INFORMASI PADA DUNIA KEDOKTERAN : PELUANG DAN HAMBATAN PENERAPAN PENGOBATAN JARAK JAUH," pp. 1-4, 2006.

A. Yani, "KESEHATAN MASYARAKAT UTILIZATION OF TECHNOLOGY IN THE HEALTH OF COMMUNITY HEALTH," vol. 8, 2018.

D. Kurnia, "IDENTIFIKASI OBESITAS PADA BALITA DI POSYANDU BERBASIS ARTIFICIAL INTELLIGENCE," vol. 1, pp. 76-86, 2018.

R. Hariyanto, P. Studi, T. Informatika, F. T. Informasi, and U. M. Pasuruan, "Sistem Pakar Diagnosis Penyakit dan Hama Pada Tanaman Tebu Menggunakan Metode Certainty Factor," vol. 3, no. 1, pp. 1-4, 2018.

B. F. Yanto et al., "Aplikasi Sistem Pakar Diagnosa Penyakit Pada Anak Bawah Lima Tahun Menggunakan Metode Forward Chaining," vol. 3, no. 1, 2017.

C. H. Primasari, "Aplikasi Web Sistem Pakar untuk Diagnosis Penyakit Gizi," no. 43.

I. H. Santi, B. Andari, T. Informasi, A. Negara, U. Islam, and B. Blitar, "Sistem Pakar Untuk Mengidentifikasi Jenis Kulit Wajah dengan Metode Certainty Factor," vol. 3, no. 2, pp. 159-177, 2019.

F. Hadi, "IMPLEMENTASI SISTEM PAKAR BERBASIS ATURAN UNTUK DIAGNOSA PRODUKTIVITAS TERNAK AYAM RAS DENGAN," vol. 23, no. 2, pp. 1-11, 2016.

M. Arifin, W. Eka, and Y. Retnani, "Penerapan Metode Certainty Factor Untuk Sistem Pakar Diagnosis Hama Dan Penyakit Pada Tanaman Tembakau."

R. Yulianti, M. Abdassah, R. Abdulah, and E. Surachman, "Gel Kombinasi Ekstrak Daun Sirsak dan Daun Jambu Biji Sebagai Obat Anti Jerawat," vol. 7, no. 3, pp. 183-189, 2015.

S. Pelen, A. Wullur, and G. Citraningtyas, "FORMULASI SEDIAAN GEL ANTIJERAWAT 
MINYAK ATSIRI KULIT BATANG KAYU MANIS

( Cinnamomum burmanii ) DAN UJI AKTIVITAS

TERHADAP BAKTERI Staphylococcus aureus," vol. 5, no. 4, pp. 136-144, 2016.

[13] D. I. Sekitar, P. Di, and K. Sentosa, "Jurnal Indobiosains. Vol 1. No. 2 Edisi Agustus 2019 http://univpgri-

palembang.ac.id/e jurnal/index.php/biosains," vol. 1, no. 2, pp. 76-87, 2019.

[14] Y. Indrianingsih, P. Studi, T. Informatika, S. Tinggi, and T. Adisutjipto, "Deteksi jerawat pada wajah menggunakan metode viola jones."

[15] E. Pemberian et al., "TERHADAP JERAWAT PADA REMAJA Pendahuluan Jerawat adalah kondisi abnormal kulit akibat terjadi gangguan berlebihan produksi dengan presentasi antara 36-66 \% dengan ekskresi bahan kimia dari propionibacterium," vol. 2, no. 1,2019 
